\title{
Estratégias cognitivas de escrita do português do Brasil ${ }^{1}$
}

\author{
Luciene Miranda - Universidade Salgado de Oliveira, Juiz de Fora, Brasil \\ Márcia Maria Peruzzi Elia da Mota² - Universidade Salgado de Oliveira, Niterói, Brasil
}

\begin{abstract}
Resumo
Estudos sobre o processamento da escrita têm focado no papel do processamento fonológico na escrita; poucos estudos investigam os estágios posteriores dessa aquisição. Este estudo foi direcionado a crianças do segundo e terceiro ano do ensino fundamental que realizaram um ditado experimental composto de palavras com diferentes características ortográficas. Visou-se verificar o papel do processamento fonológico e morfológico na escrita a partir de uma análise qualitativa dos erros cometidos pelas crianças no ditado. Foi possível verificar que a maioria dos erros (mais de $80 \%$ ) foi de natureza fonológica. Nessa faixa etária o processamento morfológico não pareceu ser uma estratégia dominante na escrita das crianças.

Palavras-chave: Habilidades metalinguísticas, Processamento fonológico, Processamento morfológico, Escrita.
\end{abstract}

\section{Cognitive writing strategies in brazilian portuguese}

\begin{abstract}
Studies about writing processing have focused in the role of phonological processing in writing. Few studies investigate the later stages of this acquisition. This study was directed to second and third grade children. They had to answer an experimental writing task that was composed by words with different orthographic characteristics. The aim was to verify phonological and morphological processing in writing based on the qualitative analyses of children's spelling errors. Most of the errors (more than $80 \%$ ) were phonological in nature. In this age group morphological processing does not seem to be a dominant strategy in writing.

Keywords: Metalinguistic abilities, Phonological processing, Morphological processing, Writing.
\end{abstract}

O princípio alfabético é o de que as letras (grafemas) correspondem aos sons (fonemas) da fala. Não obstante, as línguas alfabéticas variam quanto ao grau de correspondência entre letra e som. Em outras palavras, nem sempre essas regras de correspondência se aplicam ou são claras. Palavras com "geleia" ou "jiló" poderiam perfeitamente ser escritas como "jeleia" e "giló" se as regras de correspondência entre letra e som fossem aplicadas.

Meireles e Correa (2005) ressaltam que os conhecimentos mais básicos da associação entre letras e sons não são suficientes para que a criança domine o sistema de escrita do português de maneira correta e consistente. Faz-se necessário que a criança conheça os aspectos ortográficos da língua e saiba lançar mão dos mesmos, o que aparece como mais uma fonte de dificuldades. A criança precisa analisar a língua de maneira mais complexa, assim como conhecer diferentes regras ortográficas.

Um dos modelos cognitivos mais clássicos de aquisição da leitura e escrita foi proposto por Frith (1985). A autora investigou características do desenvolvimento da leitura e escrita da criança, possibilitando assim que pesquisas posteriores pudessem relacionar essas características à emergência

\footnotetext{
1 Agradecimentos ao financiamento da FAPEMIG Processo No: APQ00679-08.

Agradecimentos às alunas Renata Miguel, Géssica Castelani, Leonice Rezende e Maira Toledo, que auxiliaram na coleta dos dados.

${ }^{2}$ Endereço para correspondência:

E-mail: mmotapsi@gmail.com
}

das habilidades metalinguísticas e sua relação com o aprendizado. A autora destacou que a aprendizagem das regras de correspondência entre letra e som não seriam suficientes para explicar a escrita proficiente, uma vez que nem sempre essas regras se aplicam. Segundo a autora, o desenvolvimento das habilidades de leitura e da escrita ocorre em três fases diretamente relacionadas com três estágios denominados, por ela, como logográfico, alfabético e ortográfico.

O modelo proposto por Frith (1985) tem como base a teoria da rota dupla que propõem duas rotas de reconhecimento de palavras. Uma rota visual, na qual o reconhecimento se dá pelo reconhecimento das palavras como um todo ou como sequência de letras ou pela rota alfabética que envolve a aplicação das regras de correspondência entre letra e som.

Embora o modelo da rota dupla esteja caindo em desuso, ele destaca o fato de que o conhecimento ortográfico precisa ser dominado pelo aprendiz. Assim, o modelo de Frith (1985) prediz que incialmente as crianças apresentariam, primordialmente, uma estratégia alfabética na escrita e a estratégia ortográfica apareceria mais tarde, na medida que a criança percebesse que o princípio alfabético não explica todas as grafias de sua língua.

Frith (1985) investigou a escrita em crianças de língua inglesa. $O$ inglês, embora seja uma língua alfabética, possui muitas exceções à escrita convencional. Seria importante saber se no português, que tem características diferentes do inglês, observaríamos a mesma sequência no desenvolvimento da escrita. Essas diferenças entre as duas línguas foram 
descrita, por Seymour, Aro e Erskine (2003), que fizeram uma descrição do grau de transparência das línguas europeias.

Línguas transparentes são aquelas que têm correspondência entre letra e som bastante clara e línguas opacas, aquelas com muitas exceções e ambiguidades em relação às regras de correspondência entre letra e som. Segundo os autores, o inglês é uma língua com estrutura silábica complexa e ortografia opaca. Muitas das irregularidades encontradas no inglês podem ser explicadas pela estrutura morfológica das palavras (Chomsky \& Halle, 1968; Sterling, 1991). Por isso o processamento das palavras em seus morfemas pode ajudar as crianças a ler e escrever nessa língua. Por sua vez, o português se encontra em um nível intermediário. Tem estrutura silábica simples, mas, no que diz respeito à transparência da ortografia, é menos opaca que o inglês e o francês, mas é mais opaca que línguas como o finlandês e o espanhol ou, ainda, o italiano. Assim, podemos pensar que o processamento morfológico pode ter um papel importante no português. Por outro lado, pode-se argumentar que não é tão importante assim. Essa é uma questão empírica que vem sendo investigada, mas que ainda precisa ser explorada.

Estudos nacionais têm apresentado alguma indicação que o processamento morfológico tem um papel no desenvolvimento ortográfico (Mota, 1996; Mota \& Santos, 2009). Queiroga, Lins, e Pereira (2006) mostraram uma evolução entre o $3^{\circ}$ e $4^{\circ}$ ano na escrita de palavras e pseudopalavras e na explicitação do conhecimento morfossintático. Encontrou-se também um efeito facilitador do conhecimento morfossintático para a escrita.

Em outro estudo investigando essa questão, Mota e Silva (2007) observaram que as crianças de segundo e terceiro ano com melhores escores nos testes de consciência morfológica eram também as que escreviam melhor pseudopalavras com ortografia morfologicamente complexa. Numa das tarefas aplicadas, a criança tinha de escrever uma pseudopalavra morfologicamente complexa que permitia a escolha de pelo menos duas formas gráficas, porém para que as regras de derivação e flexão da língua portuguesa fossem obedecidas, as crianças tinham de seguir a grafia da palavra de origem. Por exemplo, se dizia à criança: "Uma árvore que dá FRAUXA é uma ?". Uma segunda tarefa de decisão ortográfica foi criada. Nessa tarefa a criança tinha de completar uma frase com a escolha de uma pseudopalavra derivada de uma palavra-chave. Metade das palavras-chaves era pseudopalavras, metade palavras reais. Todas com ortografia ambígua. Por exemplo, à criança era dada a pergunta: "Um lugar cheio de CARTAZ é um?". A criança tinha que escolher entre as palavras "cartazeiro" ou "cartaseiro". Os resultados mostraram que, quanto ao desenvolvimento ortográfico, as crianças do terceiro ano tiveram melhor desempenho do que as crianças de segundo ano nas tarefas de escrita. Esses resultados estão de acordo com os encontrados por Nunes, Bindman e Bryant (1997), que verificaram que há um desenvolvimento no entendimento das regras ortográficas que envolvem a morfologia da língua. Os autores argumentam que esse entendimento começa apenas depois que as crianças dominam o conhecimento das regras de correspondência entre letra e som da língua, por volta do terceiro ano. As crianças de segundo puderam resolver cerca de 50\% dos itens em cada um dos testes de escrita. Como existiam duas possíveis grafias para cada palavra, esses resultados indicam que as crianças de segundo ano estavam resolvendo a tarefa no nível de chance. No terceiro ano o índice de acerto supera o nível de chance para as duas tarefas de ortografia, sugerindo que as crianças aplicam seu conhecimento morfológico na escrita.

Os estudos sobre esse tema no âmbito nacional ainda são poucos. As pesquisas sobre o desenvolvimento da escrita em geral focam nos estágios iniciais da aquisição da escrita, no período em que a criança está aprendendo as regras de correspondência entre letra e som. Assim, o que ocorre no estágio ortográfico ainda é pouco explorado. Embora não esteja no escopo deste trabalho estabelecer um modelo de desenvolvimento cognitivo da escrita para o português, os estudos discutidos chamam a atenção para o fato de que a escrita envolve um processamento em vários níveis, não apenas $\mathrm{o}$ fonológico. Nosso objetivo é explorar o papel do processamento fonológico e morfológico na aquisição da língua escrita.

Realizar uma análise qualitativa de erros de grafia pode fornecer dados bastante relevantes para estudos nesta área. Meireles e Correa (2005) discorrem sobre a importância da realização deste tipo de análise. Segundo as autoras, os erros não são meras cópias imperfeitas realizadas pela criança, mas, na verdade, consistem em tentativas válidas de escrever palavras a partir de suas próprias ideias sobre a escrita, refletindo o atual nível de elaboração da criança acerca do conhecimento ortográfico. Este motivo justifica nossa proposta de análise qualitativa neste trabalho.

Para esta análise qualitativa será utilizada a categorização de erros de Correa e Dockrell (2007). O uso da categorização proposta por estas autoras ocorre pelo fato de categorizarem os erros do tipo fonológico, morfológico, e apresentando ainda outros tipos de 
erros que podem aparecer na grafia de crianças dessa faixa etária, oferecendo uma melhor compreensão das estratégias cognitivas utilizadas pelas crianças na escrita do português.

\section{Método}

\section{Participantes}

A amostra consistiu de 57 alunos, 24 do segundo ano (média de idade 95,7 meses, $\mathrm{DP}=5,16)$ e 33 do terceiro ano do ensino fundamental (média de idade 108,1 meses, $\mathrm{DP}=4,29)$, matriculados em uma escola federal da zona urbana de Juiz de Fora. A média de idades de toda a amostra foi de 102,8 meses $(\mathrm{DP}=7,70)$. A participação na pesquisa foi voluntária. O critério de inclusão no estudo foi a assinatura de um termo de consentimento livre e esclarecido (TCLE), o qual foi submetido ao Comitê de Ética e Pesquisa (CEP) da UFJF. Participaram apenas as crianças que concordaram com a participação e obtiverem autorização escrita no TCLE.

\section{Instrumento: Ditado experimental}

As crianças foram submetidas a um ditado contendo palavras iniciadas com os prefixos "en", "in" e "des", ditadas em uma ordem aleatória. Foram escolhidas palavras morfologicamente complexas, que, de modo geral, não possuíam regras morfossintáticas claras. Foram selecionadas 24 palavras, metade delas derivadas (como "inútil") e a outra metade de palavras pseudoprefixadas (como "início"). As palavras derivadas e pseudoprefixadas foram igualmente divididas em palavras em que os prefixos ficavam intactos, correspondendo a sílabas (como em "infeliz") e nas quais os prefixos não formavam uma única sílaba (como em "in-ativo"). Os pares de palavras foram emparelhados pelo número de letras. Para garantir o pareamento por som e número de letra não pareamos as palavras por frequência de ocorrência. Assim, as palavras foram balanceadas quanto à complexidade e dificuldade ortográfica.

Um ponto foi dado para cada resposta correta. Assim, o total de pontos possíveis no ditado era 24 , sendo 6 pontos para palavras pseudoprefixadas em que os prefixos não formam uma sílaba; 6 pontos para palavras derivadas que os prefixos não formam uma sílaba; 6 pontos para palavras pseudoprefixadas em que os prefixos formam uma sílaba e 6 pontos para palavras derivadas em que os prefixos formam uma sílaba. Importante destacar que, para ser considerado um acerto, a criança precisaria escrever a palavra totalmente correta (considerando-se ortografia e acentuação).

Para verificar as estratégias de escrita foi utilizada a análise de erros de grafia de crianças, proposta por Correa e Dockrell (2007). As pesquisadoras agruparam os erros em quatro categorias que abordam o uso de informações fonológicas e morfológicas para a escrita, as quais serão descritas a seguir:

Categoria 1 - Sequência de letras: sequência de letras escrita, porém, que não representa uma palavra existente na língua portuguesa.

Categoria 2 - Erros de grafia fonologicamente aceitos: grafia errônea da representação de um fonema por uma sequência de letras cuja representação dos sons pode ser plausível, como, por exemplo, escrita de "soológico" para "zoológico".

Categoria 3 - Erros de grafia fonologicamente incorreta, categoria que inclui erros do tipo:

a) representação de letras ilegal: representação de um fonema com uma letra ou grupo de letras que não representa o som desejado em nenhum contexto da língua, como, por exemplo, atribuir a grafia errônea "priga" para "briga";

b) omissões de letras: omissão de letras que representam um fonema, como, por exemplo, atribuir a grafia "lida" para "linda"; erros relacionados à omissão das marcas de nasalização, como, por exemplo, atribuir a grafia "bricou" para "brincou";

c) ordem errônea de letras: representação de fonemas a partir de uma ordem incorreta das letras, como, por exemplo, atribuir a grafia "crotou" para "cortou".

Categoria 4 - Erros morfológicos: erros relacionados à omissão (por exemplo, atribuir a grafia "mora" para "morar"), adição (por exemplo, atribuir a grafia "uma acidente" para "um acidente") e substituição de morfemas (por exemplo, atribuir a grafia "viverão" para "viveram").

Categoria 5 - Acrescentamos a categoria "outros" para categorizar erros cometidos pelas crianças que não se enquadravam em nenhuma das categorias propostas pelas pesquisadoras.

\section{Procedimento}

As crianças foram submetidas às tarefas na própria escola onde estavam matriculadas. A aplicação da tarefa se deu em uma sessão de aproximadamente vinte minutos. Organizaram-se pequenos grupos de, no máximo, seis crianças para a realização do ditado. As palavras foram ditadas aleatoriamente para as crianças.

\section{Resultados}

A Tabela 1 apresenta a média e o desvio padrão para os acertos das crianças no ditado por série escolar e por tipo de palavra. 
Tabela 1. Médias e desvio padrão dos acertos de grafia em cada categoria do ditado morfológico experimento 2 agrupados por série e de toda a amostra

\begin{tabular}{lcccc}
\hline \multicolumn{1}{c}{ Categoria } & $\begin{array}{c}\text { Máximo } \\
\text { possível de } \\
\text { acertos (N) }\end{array}$ & $\begin{array}{c}2^{\circ} \text { Ano } \\
\text { Média (DP) }\end{array}$ & $\begin{array}{c}3^{\circ} \text { Ano } \\
\text { Média (DP) }\end{array}$ & $\begin{array}{c}\text { Média (DP) de } \\
\text { toda a amostra }\end{array}$ \\
\hline Não-sílaba pseudoprefixada & 6 & $3,5(1,4)$ & $4,9(1,1)$ & $4,3(1,4)$ \\
Não-sílaba derivada & 6 & $3,2(1,4)$ & $3,9(0,9)$ & $3,6(1,2)$ \\
Sílaba pseudoprefixada & 6 & $4,2(1,5)$ & $4,4(0,9)$ & $4,3(1,2)$ \\
Sílaba derivada & 6 & $3,6(1,5)$ & $3,4(1,4)$ & $3,5(1.4)$ \\
\hline
\end{tabular}

Análises de variância não-paramétricas MannWhitney feitas comparando o desempenho no ditado entre as séries mostraram que, com exceção do grupo de pseudoprefixadas cujos prefixos não formam sílabas $(\mathrm{z}=-3,75, \mathrm{p}<0,001)$, não houve diferenças significativas entre o número de vezes que as palavras foram escritas corretamente. Assim, não se observou um padrão de erros diferente no desenvolvimento do segundo para o terceiro ano. A análise qualitativa dos erros procedeu sem considerar as séries, colapsando os escores dos dois grupos de alunos.

A análise qualitativa dos erros de escrita permite que possamos inferir o tipo de estratégia cognitiva utilizada pelas crianças. Para verificar as estratégias de escrita, foi utilizada a análise de erros de grafia de crianças proposta por Correa e Dockrell (2007), descrita na sessão "Métodos".

A categorização dos erros cometidos em cada uma das categorias anteriormente enumeradas foi feita por dois juízes, com intuito de se evitarem problemas na interpretação das categorias de erro. Inicialmente, foram analisadas qualitativamente 163 palavras cuja grafia foi corrigida como incorreta. Os juízes concordaram na classificação de $97 \%$ destas. Nas palavras em que houve divergência na categorização, um terceiro juiz foi chamado para fazer sua categorização e decidiu-se pela classificação do terceiro juiz. A Tabela 2 mostra a frequência de ocorrência de cada tipo desses erros acima categorizados. É possível observar que a maioria dos erros encontra-se nas categorias erros de grafia fonologicamente incorreta e erros de grafia fonologicamente aceitos $(38 \%$ e $44 \%$ de erros nessas categorias, respectivamente). Os erros morfológicos e de sequência de letras combinados compuseram $6 \%$ dos erros nesse corpus.

Tabela 2. Frequência de ocorrência e porcentagem de erros de toda a amostra segundo categorização de Correa \& Dockrell (2007)

\begin{tabular}{lcc}
\hline \multicolumn{1}{c}{ Tipo de Erro } & $\begin{array}{c}\text { Freqüência de } \\
\text { ocorrência }\end{array}$ & Porcentagem \\
\hline 1- Sequência de letras & 4 & $2 \%$ \\
2- Erros de grafia fonologicamente aceitos & 62 & $38 \%$ \\
3- Erros de grafia fonologicamente incorreta & 72 & $44 \%$ \\
4- Erros morfológicos & 6 & $4 \%$ \\
5- Outros erros & 19 & $12 \%$ \\
\hline Total & 163 & $100 \%$ \\
\hline
\end{tabular}

\section{Discussão}

Este estudo pretendeu investigar as estratégias de escrita utilizadas por crianças brasileiras. Em particular, estávamos interessados em saber se a estrutura morfológica das palavras atua como um facilitador na escrita das crianças no início da escolarização. Para investigar essa questão, palavras morfologicamente complexas e simples, pareadas pelo grau de dificuldade ortográfica e complexidade fonológica, foram selecionadas para compor o ditado. Como as palavras foram pareadas pelo grau de complexidade ortográfica, predisse-se que um maior número de erros fonológicos do que morfológicos e de sequência de letras indicariam uma predominância do uso das regras de correspondência entre letra e som no processamento da escrita no português, mesmo quando as palavras fossem morfologicamente complexas.

A análise quantitativa dos erros não mostrou diferenças entre as séries escolares para a maioria das palavras. Esse resultado pode ser em razão das palavras poderem ser escritas por correspondência entre letra e som.

Em relação à análise qualitativa dos erros, Corrêa (2009) observou em seus resultados que crianças da primeira à terceira série evidenciaram padrões de escrita alfabética, caracterizada por letras 
foneticamente adequadas para representar os sons das palavras, porém, não necessariamente corretas. Os nossos resultados foram parecidos com os da amostra do estudo supracitado, ocorrendo 62 erros de grafia fonologicamente aceitos, tais como "infelis", "engeça", dentre outras palavras, sendo este o segundo tipo mais frequente de erro.

No estudo de Correa e Dockrell (2007) os erros fonologicamente aceitos foram o tipo de erro predominante dentre as crianças do estudo, alunas da primeira à terceira séries do ensino fundamental. $\mathrm{O}$ tipo de erros mais frequente nesse estudo foi o de grafia fonologicamente incorreta (72 ocorrências), categoria que englobava três subtipos de erros: representação de letras ilegal, como no caso de "inúdio"; omissão de letras, como no caso de "ifinito"; e ordem errônea de letras. No nosso caso não houve nenhum erro que se enquadrasse nessa categoria.

Um tipo de erro pouco frequente foi o do tipo morfológico, com apenas seis ocorrências. Merece destaque uma criança que cometeu uma série de erros morfológicos, separando os prefixos ou pseudoprefixos que são unidades destacáveis, como "des-colore", "e-numera", "des-carta", "des-ordem", "des-une". Esse fato é destacado, pois mostra a adoção sistemática da análise morfológica das palavras por essa criança. Embora esse não tenha sido um padrão observado em outras crianças, seria interessante que estudos futuros observassem se há um grupo particular de crianças que apresenta esse padrão de análise da escrita.

Duas considerações precisam ser feitas a partir desses resultados. A primeira diz respeito aos erros morfológicos. Nos resultados de Correa e Dockrell (2007), esse também foi um tipo de erro pouco frequente. Esses resultados podem ter relação com as séries escolares estudadas. Nunes e Bryant (2006) e Nagy, Berninger e Abbot (2006) consideram que o processamento morfológico só ocorre no final do ensino fundamental, entre o quarto e sexto ano.

A segunda diz respeito à importância do processamento fonológico na escrita. Mota, Moussatchè, Castro, Moura e D'Angelis (2000) analisaram os erros cometidos por adolescentes numa redação. Os resultados da análise quantitativa desses erros apontam a importância da aquisição do princípio alfabético na escrita, pois muitos dos erros encontrados foram causados por uma aplicação simples de regras de correspondência entre som e letra, desconsiderando o fato de que a grafia de determinadas palavras depende de regras ortográficas mais complexas, como, por exemplo, a grafia "tivece" para a palavra "tivesse".

Um dado merece ser comentado, erros fonológicos são causados porque as crianças escrevem como falam. Alguns tipos de erros de escrita ocorrem a partir de gírias e regionalismos, caracterizando erros de características fonológicas (Mota e cols., 2000). Esses tipos de erros são atribuídos à errônea associação entre letras e sons (relação entre os sons expressos na pronúncia coloquial das palavras e as letras que compõem sua ortografia). No caso dos mineiros, é observada uma tendência a encurtar as palavras (pronunciar a palavra "mesmo" como "mês"). Alguns dos erros que observamos nesse estudo merecem ser mencionados, como, por exemplo, "engés" (engessa). Essa observação reforça a conclusão de que as crianças "escrevem como falam". Esses erros apresentam mais evidências para a importância do processamento fonológico na escrita do português do Brasil.

Estudos futuros devem estudar a transição do estágio alfabético para o ortográfico com crianças mais velhas e utilizando um escopo maior de palavras, que abranjam vários níveis de dificuldades ortográficas. Conhecer esse processamento pode oferecer subsídios para educadores das séries mais avançadas do ensino fundamental para o desenvolvimento de estratégias de ensino da ortografia da língua portuguesa.

Uma última questão que precisamos apontar é que uma limitação desse estudo foi não investigar o tipo de método de alfabetização utilizado para ensinar essas crianças. De um modo geral, os métodos educacionais brasileiros privilegiam as estratégias fonológicas. A ortografia, quando ensinada, foca na memorização de padrões gráficos e não na reflexão da morfologia da língua. Talvez, essas práticas tenham influenciado nossos resultados. Seria importante investigar mediante estudos de intervenção. Entender como as palavras são formadas, por meio de outras, ajudaria na escrita de palavras complexas.

\section{Referências}

Correa, J. \& Dockrell, J. E. (2007). Unconventional word segmentation in Brazilian children's early text production. Reading and Writing: An Interdisciplinary Journal, 20(8), 815-831.

Corrêa, M. F. (2009). Como os adultos aprendem a ler? (Dissertação de Mestrado). Belo Horizonte: Universidade Federal de Minas Gerais - Instituto de Psicologia.

Frith, U. (1985). Beneath the surface of developmental dyslexia. Em K. E. Patterson \& Marshall Coltheart (Eds.). Surface dyslexia: cognitive and neuropsychological studies of phonological reading (pp. 301-330). Hillsdale, NJ: Lawrence Erlbaum.

Lemle, M. (1995). Guia do alfabetizador. São Paulo: Ática. 
Meireles, E. S. \& Correa, J. (2005). Regras contextuais e morfossintáticas na aquisição da ortografia da língua portuguesa por criança. Psicologia: Teoria $e$ Pesquisa, 21(1), 77-84.

Mota, M. M. (1996). The role of grammatical knowledge in spelling. (Tese de Doutorado). Oxford University.

Mota, M. M. \& Silva, K. (2007). Consciência morfológica e desenvolvimento ortográfico: um estudo exploratório. Psicologia em Pesquisa, 1(2), p. 86-92.

Mota, M. M. \& Santos, A. A. (2009). O papel da consciência fonológica na leitura contextual medida pelo Cloze. Estudos de Psicologia, 14(3), $207-$ 212.

Mota, M. M., Moussatchè, A. H., Castro, C. R., Moura, M. L. S. \& D'Angelis, T. (2000). Erros de escrita no contexto: uma análise na abordagem do processamento da informação. Psicologia. Reflexão e Crítica, 13(1), 01-06.

Nagy, W., Berninger, V. \& Abbot, R. (2006). Contributions of morphology beyond phonology to literacy outcome of upper elementary and middle-school students. Journal of Educational Psychology, 98(1), 134-147.

Nunes, T. (1992). Leitura e escrita: processos e desenvolvimento. Em E. S. Alencar (Org.). Novas contribuicões da psicologia aos processos de ensino $e$ aprendizagem (pp. 13-50). São Paulo, SP: Cortez.

Nunes, T. \& Bryant, P. (Org.). (2006). Improving literacy by teaching morphemes. Nova Iorque, USA: Routledge.

Nunes, T., Bindman, M. \& Bryant, P. (1997). Morphological strategies: developmental stages and processes. Developmental Psychology, 33(4), 637-649.

Queiroga, B., Lins, M. \& Pereira, M. (2006). Conhecimento morfossintático e ortografia em crianças do ensino fundamental. Psicologia: Teoria e Pesquisa, 22(1), 95-99.

Seymour, P., Aro, M. \& Erskine, J. (2003). Foundation literacy acquisition in European orthographies. British Journal of Psychology, 94, 143-174

Sterling, C. (2001). Introduction to the psichology of spelling. Em C. Sterling \& C. Robson (Orgs.). Psychology, Spelling \& Education (pp. 1-15). Clevedon: Multilingual Matters.

Recebido em 15/06/2010

Reformulado em 02/02/2011

Aprovado em 16/05/2011

Sobre as autoras:

Luciene Miranda é psicóloga, especialista em Desenvolvimento Humano e mestra em Psicologia pela Universidade Federal de Juiz de Fora. Atualmente é professora da Universidade Salgado de Oliveira - Campos Juiz de Fora.

Márcia Maria Peruzzi Elia da Mota é psicóloga, doutora em Psicologia pela Universidade de Oxford e professora titular do Programa de Pós-Graduação em Psicologia da Universidade Salgado de Oliveira - Campus Niterói. É, também, bolsista de Produtividade $2 \mathrm{CNPq}$ 